\title{
Property Outlaws in Cyberspace and Meatspace? Examining the Relationship between Online Peer Production and Sup- port for Private Property Violations
}

\author{
Timothy A. Gibson
}

George Mason University, Fairfax, Virginia, USA, tgibson1@gmu.edu

\begin{abstract}
Marxian theory has long viewed the institution of private property as central to labour exploitation. After all, private property laws allow those who control the means of production to expropriate surplus value from the dispossessed. An analogous relationship arguably defines life on the Internet, where users are forced to venture onto privately owned digital enclosures to access key services. Yet these online property relationships are anything but settled and uncontested. Outside the digital enclosures of Apple and Google, the Internet has fostered the development of "commons-based peer production", where key resources (e.g. software) are produced without anyone claiming exclusive property rights. In fact, some scholars have argued that the rise of peer production on the web has begun to re-shape popular attitudes concerning the legitimacy of property exclusions more broadly. In short, as we become "property outlaws" on the web, we come to question the inevitability and legitimacy of private property elsewhere in life. This paper explores this hypothesis by reporting data from a survey of Internet users at an East Coast university. Are users who engage in more peer production activities on the web also more likely to approve of "property outlaw" behaviours not just in the online context, but in the offline world as well (e.g. squatting)? The data provide only partial support for the hypothesis: active online peer producers were indeed more likely to support violations of intangible (intellectual) properties, but not violations of tangible or "real-world" properties.
\end{abstract}

Keywords: Intellectual property, internet commons, online peer production, political ideology, Marxian theory

Marxian theory has long viewed the institution of private property as central to the exploitation of labour in capitalism. After all, laws protecting private property allow those who control the means of production to expropriate surplus value from the propertyless and dispossessed. As Andrejevic (2007) argues, an analogous relationship increasingly defines life on the Internet, where users are forced to venture onto privately owned digital enclosuresthink: Google, Apple, and Facebook-to access services that are fast becoming nonnegotiable and necessary for the conduct of everyday life. The price of access, of course, is submission to a regime of commercial surveillance and what Andrejevic (2003) aptly calls "the work of being watched".

Yet these online property relationships are anything but settled and uncontested. Outside these digital enclosures, the Internet has also fostered the development of what Yochai Benker (2006) calls "commons-based peer production", where key resources (e.g. software) are produced collectively without anyone claiming exclusive property rights. In fact, some scholars have argued that the rise of commons-based peer production on the web-along with other practices which directly challenge the sanctity of intellectual property (e.g. filesharing)- has begun to re-shape popular attitudes concerning the legitimacy of property exclusions more broadly. In short, as we become "property outlaws" on the web, we come to question the inevitability and legitimacy of private property elsewhere in life (Lessig 2008; Peñalver and Katyal 2010).

After a review of recent work on property relationships and struggles over intellectual property rights in the online context, this article explores this hypothesis-the more we become property outlaws online, the more we support property violations offline as well-by reporting opinion data from a survey of young Internet users at a public university on the East Coast of the USA. The central research questions pursued in the survey were therefore 
straightforward: Were users who engaged more often in peer production activities on the web (such as "remixing" videos on YouTube or editing entries on Wikipedia) also more likely to approve of violations of copyright on the web? More intriguingly, were online peer-producers also more likely to approve of "property outlaw" behaviours offline as well (such as squatting or illegal sit-in protests)?

The initial data provide only partial support for the study's hypotheses. Those students who engaged in more peer production on the web indeed held more positive attitudes about online "outlaw" behaviours which directly challenged the sanctity of intellectual property laws. At the same time, as reported below, the relationship between online peer production and support for "real-world" property outlaws in the offline world was much more ambiguous. Overall, the data failed to show a significant relationship between online peer production and attitudes about "real-world" property outlaws. However, a tentative post-hoc analysis suggests that the heaviest online peer producers indeed voiced more support for real-world property violations (e.g. squatting, sit-ins, etc.), especially when compared to those students who engaged in one or fewer of these online peer production activities. A concluding section discusses the potential theoretical and political implications of these suggestive findings.

\section{Literature Review}

The critique of capitalist regimes of property has been at the centre of Marxian economic and social theory from the very beginning. And rightly so. After all, the origins of capitalism lay in the bloody history of what Marx called "primitive accumulation", during which once-collective agricultural resources were seized by the state, sold off or simply handed to private owners, and thereafter thrust into the circuit of capital accumulation (Wood 2002). This process of primitive accumulation, or what David Harvey (2003) has called "accumulation by dispossession", of course continues in myriad forms today, perhaps most notably (and disruptively) in the privatization of collective resources in China and India (Harvey 2005).

Moreover, as Heilbroner (1986) notes, the very engine of capital accumulation-the exploitation of living labour-depends on a very particular regime of private property. In this regime, it is the capitalist (the owner of the means of production) who enjoys property ownership over what is produced by the firm. For their part, wage labourers enjoy no such rights. Everything workers produce-every product, every ounce of surplus-immediately becomes the property of the firm and its investors. For Marxian critics, this property relation is thus the beating heart of capitalist exploitation and the ultimate source of the inequality and injustice in capitalist societies (Cohen 1988). And indeed, for many Marxian scholars, the primary purpose of the liberal state itself is to protect and guarantee this fundamentally exploitative regime of property rights.

For this reason, as Peñalver and Katyal (2007) argue, laws protecting private property have been a source of controversy and struggle throughout the history of capitalism. Interestingly, however, they argue that although much critical legal scholarship has been devoted to "how private property rights emerged from commons-based systems", relatively little attention has been focused on individual and collective struggles which, although not challenging the core system of bourgeois property rights, nonetheless reform property laws in ways which benefit workers and the dispossessed (Peñalver and Katyal 2007, 1100).

According to Peñalver and Katyal (2007), a central figure in these periodic struggles over the scope and content of property rights is the "property outlaw". The history of capitalist societies is replete with examples of how the public, intentional violation of property laws can push the political system into reforms which reduce the injustice of existing property arrangements. As the authors note:

Property outlaws have played a crucial role, time and again, in drawing attention to the need for reform. As we show, property outlaws offer two important sources of value. First, they can sometimes contribute to efficient or justified forced transfers of entitlements, generating what we will call "redistributive value." Second, protracted and pervasive property law-breaking produces important data about the location of possi- 
ble injustice or inefficiency within the property status quo, generating what we will call "informational value." (Peñalver and Katyal 2007, 1103)

For example, the authors note that during the $19^{\text {th }}$ century the US federal government sold off huge tracts of Western land to East Coast speculators, who typically left it vacant and unimproved as they waited patiently for prices to rise. Such practices of course encouraged rampant squatting among settlers looking to build homesteads on the frontier, and absentee landlords quickly found it difficult to enforce their property rights from a distance. Ultimately, the settlers' fierce resistance paid off in two ways: first, in securing the passage of adverse possession statutes in local legislatures (which, in certain cases, legalized title transfers from absentee landlords to squatters); and, second, in slowly steering federal public lands policy toward the interests of small landholders and settlers (Peñalver and Katyal 2007, 1113).

According to Peñalver and Katyal $(2007,1102)$ there are two categories of law-breaking related to property. Acquisitive property violations refer to self-directed appropriations of others' property. With acquisitive violations, the property of others is appropriated not to send a political message or to make a statement about property rights. Instead the goal is personal: taking property to satisfy your own needs or achieve your own goals. On the other hand, political-expressive property violations are other-directed. In these cases, the property of others is appropriated not primarily to acquire a desired resource but rather to send a political message about the injustice of current property arrangements. If our $19^{\text {th }}$ century squatters offered an example of acquisitive property violations, the lunch-counter protests of the Civil Rights Movement were political-expressive violations. In short, the point of defying segregation-era property laws (which gave white storeowners the "right to exclude" based on race) wasn't the lunch. The point was to send a political message on the inhumanity of race-based exclusions from commercial and public life.

In the current moment, the most notorious property outlaws make their mark not in what novelist William Gibson might call the "meatspace" of squatting and occupying but rather in "cyberspace" as file-sharers, re-mixers, and anti-copyright hackivists. In short, just as private property regimes have extended their reach-mostly through laws that massively extend the reach and scope of copyright, trademark, and patent protections-so too have property outlaws moved online to contest this expansion.

The reasons for this ferment and struggle over the scope of intellectual (or what I will call "intangible") property rights are legion and have been covered extensively elsewhere (Lessig 2004, 2008; McLeod 2003; Boyle 2003). Chief among these reasons is of course the increasingly central role played by information, knowledge, and culture in contemporary global capitalism (Hardt and Negri, 2004; Lash and Urry 1994; Moulier Boutang 2011). To the extent that monopoly control over proprietary information is becoming more and central to future profits, we should expect firms to zealously protect their investments in intangible properties through the legal system (Coombe 1998; Mosco 2009).

At the same time, millions of people across the world have become immersed in digital culture and have developed a facility with technologies that allow for "ripping", "remixing", and "sharing" cultural content (Jenkins 2006). For these millions, the boundaries set by intellectual property laws seem arbitrary and hostile not only to creativity and free expression (as is the case when copyright owners shut down amateur YouTube "remixers"), but also to a basic sense of dignity and fairness (as happens when patents are used to shut down the production of life-giving drugs in the developing world) (Lessig 2008).

At the centre of this social movement against overly restrictive intangible property laws is arguably the experience of engaging in online "commons-based peer production," which Benkler $(2006,60)$ defines as:

A new modality of organizing production: radically decentralized, collaborative, and nonproprietary; based on sharing resources and outputs among widely distributed, loosely connected individuals who cooperate with each other without relying on either market signals or managerial commands. 
The most common example cited in this literature on non-proprietary peer production is, of course, Wikipedia. No single person or firm "owns" Wikipedia, and everyone is free to contribute content, edit content, and use it as a resource for learning. Yet it still works tolerably well and provides a leading first-look resource on an ever-expanding array of topics and subjects. As some writers have argued, the experience of contributing to Wikipedia-or, in a more specialized sense, to an open-source software project-can in fact be transformative. It is a powerful demonstration of how crucial resources can be built and shared absent profit motives, managerial control, or private property arrangements (Bauwens 2009; Rigi 2013).

At the same time, there are some complexities in the concept of peer production that require some unpacking. For instance, although Benkler has focused on the non-proprietary nature of particular high-profile peer production efforts (such as Linux, Wikipedia, and NASA's "clickworkers" program), other authors have noted that, in other cases of peer production, the lines between "commons" and "commodity" can be quite blurry (Meng and Wu 2013). For his part, Bauwens (2009) distinguishes true commons-based peer production from a competing "Web 2.0/sharing economy model." In this sharing economy model of peer production, "a proprietary platform [such as Facebook or YouTube] enables and empowers participation, usually in the form of sharing" but, depending on the terms of service, the products of users' collaboration and sharing can be effectively enclosed by the platform owners (Bauwens 2009, 126). For example, a remixed Taylor Swift video on YouTube may be the product of a distributed collaborative effort, but the "input" (the original video) is proprietary, the platform (YouTube) is proprietary, and the terms of service may give the platform owner (Google) what amounts to full property rights in the form of a world-wide license. In short, not all peer production projects are "common-based", and even the classic examples of nonproprietary peer production have developed complex relationships with the commodity system, as happens when firms develop products and services around open-source software (Kreiss, Finn, and Turner 2011).

Furthermore, if authors like Bauwens, Wu and Meng have noted the complex and interlocking relationships between commons and commodity in peer production processes, others have noted the increasingly wide range of "goods" that can be "peer produced." For instance, as Benkler (2006) notes, rating systems or product reviews, which used to be produced by professional firms (e.g. Consumer Reports) can now be peer produced (e.g. Yelp reviews). The same is true of the production of news and commentary (via communities of bloggers) and the production of cultural archives, including, for instance, amateur photographers who collectively create vast image collections (Bauwens 2009; Shirky 2008). Even social protests can be viewed as "peer produced' by a distributed network of differentially engaged users (Bennett, Segerberg, and Walker 2014).

Finally, still other authors have noted how peer production can encompass a vast range of activities across a wide spectrum of engagement and commitment levels. As Shirky (2008) argues, successful peer production projects typically offer users "granular" opportunities to participate. For instance, while some users may spend hours composing a long Wikipedia entry, others may simply edit a single sentence. Users thus self-select their level of commitment and participation, and these activities are coordinated not by top-down managerial systems but via informal group norms developed by peer producers themselves (Benkler 2006, 73).

Peer production is therefore a complicated and varied phenomenon. At the same time, despite these complexities, there is nonetheless a core feature to the experience: the collaborative production of a common good by a decentralized network of dispersed and differentially engaged individuals (Bennett, Segerberg, and Walker 2014, 59). And this participation can still be a transformative experience, the proprietary nature of the platform notwithstanding (Jenkins, Ford and Green 2013; Lessig 2008). In short, a distributed group of teens who create and share mash-ups of their favourite songs likely do not care, at least initially, if the songs are copyrighted and the sharing platform (YouTube) is privately owned. Instead, the experience of creating, in common with others, something of social value without managerial direction or market incentives offers a glimpse into a better, more participatory and equitable social world-at least until YouTube pulls their mash-up down. 
And this is the crucial point. For writers like Benkler and Lessig, it is this exposure to the free-wheeling, collaborative, creative world of online "peer production" as well as the often coercive reactions of digital property owners which feeds and nurtures contemporary cyberoutlaw activism. For one, online peer production practices (e.g., remixing Taylor Swift's latest music video with a bleating goat) often run directly afoul of copyright protections, and presumably nothing breeds a copyright outlaw quicker than pulling down a remixed video she spent hours crafting with her friends. Moreover, the ideological claims of the cultural and information industries (i.e. that creativity and innovation depends on strong IPR regimes) begin to ring hollow to users who run their laptops on open-source software (Benkler 2006).

Overall, then, it is certainly true that the dominant trends in online property arrangements point to the creation of a "digital enclosure" (Andrejevic 2007; Boyle 2003) where users are forced to venture onto privately-owned and proprietary platforms (like Google or Facebook) if they wish to access services increasingly central to everyday life. At the same time, however, widespread experience with alternative forms of production and association on the Internetincluding Wikipedia, open-source software, remixing, and online culture jamming-has inspired many users to contest this enclosure, to protest the ever-expanding reach of private property online, and to engage in forms of outlaw behaviour, including illegal music or video downloading, unauthorized remixing and sharing, and old-school "hacking" of various kinds (McLeod 2003).

For his part, Lessig (2008) has advanced the intriguing argument that widespread popular experience with re-mixing has contributed to a cultural sea change. Just as text-savvy individuals think nothing of quoting from prior written works (as I have done many times here), today's digital video and music re-mixers think nothing of sampling and quoting from commercial film, television, and music when exercising their own creative impulses. Remixing is normative for youth, Lessig argues. And the more intellectual property owners push back and criminalize this now-normative "ripping", "mixing", and "sharing", the less respect youth will have for property law (Lessig 2008, 107-109). The irony is rich. The copyright police, through their very overzealousness, are actually creating a new generation of property outlaws.

However intriguing, Lessig's argument remains speculative. To my knowledge, there has been no research as yet on the relationship between an individual's experience with online peer-production (i.e. re-mixing or engaging in the collective production of shared resources) and their attitudes on property rights and property violations. For this reason, this study begins with two straightforward research questions:

RQ1: What is the relationship between online peer production and support for acquisitive and political-expressive property outlaws?

RQ2: What is the relationship between online peer production and support for violations of tangible and intangible property rights?

This study therefore will explore whether engaging in more online peer-production behaviours leads to more positive attitudes about and support for property outlaws. Moreover, rather than remaining wholly within the realm of intangible/intellectual property (which is Lessig's main focus), this study also asks if engaging in peer-production behaviours might also be associated with more positive attitudes about property outlaws in "meatspace"-better known as the realm of tangible property. It is worth asking, in short, if individuals who subvert strict property restrictions online in the pursuit of creativity and free expression might come to view property rights elsewhere in life through the same critical lens.

To this end, this study begins with the following hypotheses, derived from the arguments of Katyal, Peñalver, Lessig, and Benkler:

H1: The more respondents engage in online peer-production behaviours, the more they will support violations of intangible property.

H2: The more respondents engage in online peer-production behaviours, the more they will support violations of tangible property. 
The research questions were explored and hypotheses tested via an exploratory survey of college students which measured, first, respondents' experience with a diverse array of online peer-production behaviours, and, second, their attitudes about the ethics of property violations in four categories: (1) acquisitive or (2) political-expressive violations of (3) tangible or (4) intangible properties. The next section discusses this methodology in more detail.

\section{Methods}

To explore the relationship between experience with online peer production and attitudes about property outlaws, I conducted a pilot survey of 171 undergraduate and graduate students at a mid-sized, public university on the East coast of the USA. The sample, recruited during Fall 2012, was a non-random, convenience sample, which of course limits the generalizability of any results. The survey itself was conducted using an online survey tool, and it was distributed through email listservs primarily to students studying communication, film, and media studies. Students outside these programs may have also taken the survey, given that participants were invited to pass the survey link along to fellow students, so long as they were currently attending the university. Finally, the survey instrument was designed to measure the two major variables in the study: peer-production experience (independent variable) and property outlaw attitudes (dependent variable).

\subsection{Independent Variable Measure - Peer Production Index}

The survey measured peer-production experience by asking ten dichotomous (yes/no) questions about respondents' web use (e.g. have you ever helped write or edit an article on Wikipedia? Have you ever produced a music "mash-up" and shared it on Facebook or YouTube? Have you ever produced a "re-mixed" video and posted this video online?). Drawing on recent scholarship (reviewed above) which argued for an expansive definition of peer production, the items were developed to include both commons-based and proprietary platforms, as well as both low- and high-commitment examples of peer production (e.g. commenting on a blog post versus contributing code to an open-source software project). Respondents' answers to these ten questions were then summed to create a peer production index, with a score ranging from zero (no peer production experience) to 10 (intensive peer production experience). The average score on this index was 2.38 , indicating that the average respondent engaged in either two or three of these ten peer-production activities. Overall, a Cronbach's alpha test revealed the peer production index to have only moderate reliability $($ alpha $=0.621)$. Although sufficient to proceed with analysis, the implications of this reliability score-a weakness in the study and most likely due to the wide range of activities listed in the index-will be discussed in the conclusion.

\subsection{Dependent Variable Measures-Property Outlaw Attitudes}

Following Peñalver and Katyal, I sought to measure respondents' views regarding the ethics of intentional property violations along two dimensions: (1) acquisitive vs. political expressive violations, and (2) tangible vs. intangible property violations. In short, as noted in the above hypotheses, I wanted to be able to assess if respondents held divergent attitudes about violations of tangible (material/real-world) and intangible (intellectual/cultural) properties. Finally, although not the primary aim of the study, I also wanted to explore if respondents felt differently about property violations primarily motivated by self-interest and achieving practical goals (acquisitive) or by the desire to send a political message (political-expressive).

To explore these attitudes, I created a series of eight hypothetical scenarios, which described particular property violations. These scenarios were specifically written to illustrate both tangible/intangible and acquisitive/political-expressive property violations. Table 1 shows how these eight scenarios created a matrix of property violations across four categories: tangible-acquisitive, tangible-political, intangible-acquisitive, and intangible-political violations. In this way, I was able to compare respondents' attitudes with regard to property violations across both the tangible/intangible and acquisitive/political-expressive dimensions. 


\begin{tabular}{|c|c|c|}
\hline & Acquisitive Outlaws & Political-Expressive Outlaws \\
\hline $\begin{array}{l}\text { Tangible Property } \\
\text { Violations }\end{array}$ & $\begin{array}{l}\text { a. Homeless families squat- } \\
\text { ting on vacant properties. } \\
\text { b. Farmers squatting on } \\
\text { under-used agricultural } \\
\text { land. }\end{array}$ & $\begin{array}{l}\text { c. Protesters camping in a private } \\
\text { plaza. } \\
\text { d. Billboard modification (i.e. "culture } \\
\text { jamming" tangible property) }\end{array}$ \\
\hline $\begin{array}{l}\text { Intangible Property } \\
\text { Violations }\end{array}$ & $\begin{array}{l}\text { e. Remixing and sharing a } \\
\text { Star Wars video. } \\
\text { f. Producing generic chicken } \\
\text { pox vaccine in a developing } \\
\text { nation without permission. }\end{array}$ & $\begin{array}{l}\text { g. Hacking an energy company's } \\
\text { website to send environmental mes- } \\
\text { sages. } \\
\text { h. Publicizing unflattering corporate } \\
\text { memos without permission. }\end{array}$ \\
\hline
\end{tabular}

Table 1: Matrix of Property Violations Measured in Survey

The actual survey questions were constructed in the following way. First, respondents were presented with a hypothetical scenario illustrating a particular property violation. For example, one question (measuring a tangible and acquisitive violation) began in this way:

\begin{abstract}
Consider the following scenario. A group of housing activists decides to help homeless families move into foreclosed houses which are currently vacant. These foreclosed and vacant houses are owned by banks, but the banks have not approved this use (i.e., the banks have not given the group permission to move homeless families into these vacant houses).
\end{abstract}

The respondents were then asked to rate the ethics of this use of the vacant houses by agreeing or disagreeing (along a five-point Likert scale) with the statement: "this use of the houses was ethical."

Respondents answers to these eight Likert-scale questions were then used to create four indexes, measuring respondents' overall attitudes concerning tangible violations (questions $a, b, c$ and $d$ in Table 1), intangible violations (questions e, $f, g$ and $h$ ), acquisitive violations (questions $a, b, e$ and f), and political-expressive violations (questions $c, d, g$ and $h$ ). In all four cases, the scores ranged between 4 (signifying very unfavourable attitudes) and 20 (signifying very favourable attitudes). As can be seen in Table 2, all four violation attitude indexes enjoyed moderate-to-high reliability. Given that the study's two hypotheses focused on students' attitudes about intangible versus tangible property violations, this comparison will be the focus of the findings section below.

\begin{tabular}{|l|l|}
\hline & $\begin{array}{l}\text { Reliability Score } \\
\text { (Cronbach's alpha) }\end{array}$ \\
\hline Intangible property violations & 0.714 \\
\hline Tangible property violations & 0.741 \\
\hline Acquisitive property violations & 0.713 \\
\hline Political-expressive violations & 0.717 \\
\hline
\end{tabular}

Table 2: Reliability Scores: Property Violation Attitude Indexes

\title{
2.3. Control Measure - Political Ideology
}

Finally, the survey attempted to control for the independent influence of one variable which might have some bearing on the relationship between online peer production activities and attitudes about property violations: political ideology. To this end, respondents' political be- 
liefs were measured with a single item: "generally thinking, do you usually think of yourself as more liberal or more conservative in your political views?" Respondents were given a range of four options to choose from: strong liberal/progressive, moderate/lean liberal, moderate/lean conservative, and strong conservative. Responses were then coded to create a conservatism index, with $1=$ strong liberal and $4=$ strong conservative. In short, the more conservative the respondent, the higher their score on the scale.

\subsection{Sample characteristics}

Overall, as can be seen in Table 3 below, the sample $(n=171)$ was split fairly evenly between men $(47 \%)$ and women (53\%) and was composed primarily of young adults, with an average age of 20 . As might be expected from a population of university students, two-thirds of the sample came from college-educated families (as measured by the level of education achieved by their mothers). Finally, in terms of political ideology, over two-thirds of the sample at least "leaned" toward liberal/progressive views (with $17 \%$ considering themselves as strong liberal/progressives).

\begin{tabular}{|l|c|c|c|}
\hline & & $\mathbf{N}$ & $\%$ \\
\hline Gender & Female & 82 & $53.2 \%$ \\
\hline & Male & 72 & $46.8 \%$ \\
\hline Age & & & \\
\hline & Average age (rounded) & 20 years old & \\
\hline Mother's education & Less than high school & 5 & $3.2 \%$ \\
\hline & High school diploma & 17 & $10.9 \%$ \\
\hline & Some college & 17 & $10.9 \%$ \\
\hline & Associate's degree & 16 & $10.3 \%$ \\
\hline & Bachelor's degree & 61 & $39.1 \%$ \\
\hline & Graduate degree & 34 & $21.8 \%$ \\
\hline & Don't know & 6 & $3.8 \%$ \\
\hline & Strong liberal & 27 & $17.4 \%$ \\
\hline Political ideology & Moderate, lean liberal & 80 & $51.6 \%$ \\
\hline & Moderate, lean con- & 43 & $27.7 \%$ \\
\hline & servative & & $3.2 \%$ \\
\hline & Strong conservative & 5 & \\
\hline
\end{tabular}

Table 3: Sample Demographics

\section{Findings}

\subsection{Frequency Results - Independent and Dependent Measures}

Table 4 shows how frequently respondents engaged in ten specific peer production activities. Not surprisingly, the more time and skill-intensive activities (e.g. open source software) had fewer participants $(8.3 \%$ of the sample), while a much higher percentage of respondents engaged in easier activities like commenting on a blog post (69.2\%). As noted above, overall, the average respondent engaged in 2.38 of these peer production activities.

\begin{tabular}{|l|c|c|}
\hline & N & $\%$ \\
\hline Have you ever helped write or edit an article on Wikipedia? & 26 & $15.3 \%$ \\
\hline Have you ever produced a music "mash-up" and shared it online? & 22 & $12.9 \%$ \\
\hline
\end{tabular}




\begin{tabular}{|l|c|c|}
\hline Have you ever produced a "re-mixed" video and posted this video online? & 14 & $8.2 \%$ \\
\hline Have you ever created a "song video" and posted this video online? & 22 & $12.9 \%$ \\
\hline $\begin{array}{l}\text { Have you ever created an Internet "meme" and shared it online (e.g., a "lol- } \\
\text { cat")? }\end{array}$ & 54 & $31.8 \%$ \\
\hline Do you have a blog that you share with others? & 50 & $29.4 \%$ \\
\hline Have you ever commented on a blog post written by someone else? & 117 & $69.2 \%$ \\
\hline $\begin{array}{l}\text { Have you ever contributed a business or product review on a consumer } \\
\text { website like Yelp or Amazon? }\end{array}$ & 74 & $43.8 \%$ \\
\hline $\begin{array}{l}\text { Have you ever posted photos on Flickr and invited other users to comment } \\
\text { upon them? }\end{array}$ & 22 & $13 \%$ \\
\hline $\begin{array}{l}\text { Have you ever contributed code to an open-source software development } \\
\text { project? }\end{array}$ & 14 & $8.3 \%$ \\
\hline
\end{tabular}

Table 4: Peer Production Activities ("yes" responses)

Table 5 reports how respondents as a whole felt about the eight property violation scenarios presented in the survey. Overall, respondents voiced the most support for producing generic versions of vaccines in developing nations without the permission of patent holders (53 percent) and producing a remixed Star Wars video in violation of copyright (41 percent). Respondents had a dimmer view of "culture jamming" a billboard to critique advertising (17 percent) and hacking an energy company's website to send pro-ecology messages (16 percent). More broadly, when their responses were summed to produce the four ethics indexes, respondents on the whole held the more favourable attitudes about intangible (vs. tangible) and acquisitive (vs. political-expressive) violations (Table 6).

\begin{tabular}{|l|l|c|c|}
\hline & \multicolumn{1}{|c|}{$\mathbf{N}$} & $\%$ \\
\hline $\begin{array}{l}\text { Tangible } \\
\text { Violations }\end{array}$ & $\begin{array}{l}\text { Homeless families squatting on vacant properties owned by } \\
\text { banks (acquisitive) }\end{array}$ & 59 & $37.1 \%$ \\
\hline & $\begin{array}{l}\text { Landless farmer squatting on unused farmland owned by dis- } \\
\text { tant landlord (acquisitive) }\end{array}$ & 32 & $20.6 \%$ \\
\hline & Protesters camping on private plaza w/o permission (political) & 32 & $20.8 \%$ \\
\hline $\begin{array}{l}\text { Intangible } \\
\text { Violations }\end{array}$ & $\begin{array}{l}\text { Remixing and sharing a Star Wars video without permission } \\
\text { (acquisitive) }\end{array}$ & 62 & $40.8 \%$ \\
\hline & $\begin{array}{l}\text { Producing generic version of vaccine in a developing nation } \\
\text { without permission (acquisitive) }\end{array}$ & 82 & $52.9 \%$ \\
\hline & $\begin{array}{l}\text { Hacking an energy company's website to send pro- } \\
\text { environment messages (political) }\end{array}$ & 25 & $16.2 \%$ \\
\hline & $\begin{array}{l}\text { Putting internal company memos regarding voting machine } \\
\text { flaws on the web without permission (political) }\end{array}$ & 61 & $39.4 \%$ \\
\hline
\end{tabular}

Table 5: Attitudes on Ethics of Property Violations (\% who agree violation is "ethical")

\begin{tabular}{|l|c|c|c|c|}
\hline & Means & $\mathbf{t}$ & $\mathbf{d f}$ & $\mathbf{p}$ \\
\hline Intangible violation attitudes & 12.1973 & -6.868 & 146 & .000 (significant) \\
Tangible violation attitudes & 10.5238 & & & \\
\hline Acquisitive violation attitudes & 12.2109 & -7.389 & 146 & .000 (significant) \\
Political-expressive violation attitudes & 10.5102 & & & \\
\hline
\end{tabular}

Table 6: Mean Scores on Violation Attitudes Indexes 


\subsection{Research Questions and Hypotheses}

As noted above, the research questions and hypotheses guiding this study focused on the relationship between students' experiences with peer production and their attitudes about property violations. These relationships were tested by computing a Pearson's correlation coefficient $(r)$ for each violation category. The results can be found in Table 7. Specifically, the first research question asked about the relationship between peer production activities and attitudes about political-expressive and acquisitive property outlaws. In short, did the experience of engaging in peer production activities lead students to feel more favourably toward property outlaws who violate property rights for political reasons (i.e. to send a public message)? And what about acquisitive outlaws? Were heavier peer producers more likely to hold positive attitudes about acquisitive violations of property? Overall, Table 7 shows that, while attitudes about acquisitive outlaws were indeed positively related to experience with peer production, attitudes about political-expressive outlaws were unrelated to peer production experience. In short, this suggests that the more students engage in peer production activities-for example, pulling copyrighted content off the web and remixing it without permission-the more likely they are to view acquisitive outlaws (like themselves, in fact) more favourably. However, this peer production experience does not necessarily translate in more favourable attitudes about politically-minded "hacktivists" and other culture-jammers who violate property laws to send public messages.

\begin{tabular}{|l|c|l|}
\hline & Pearson's r & \multicolumn{1}{|c|}{$\mathbf{p}$} \\
\hline Peer Production and Acquisitive Violation Attitudes & +0.270 & .001 (significant) \\
\hline Peer Production and Political Violation Attitudes & +0.134 & .119 (not significant) \\
\hline Peer Production and Intangible Violation Attitudes & +0.271 & .001 (significant) \\
\hline Peer Production and Tangible Violation Attitudes & +0.129 & .134 (not significant) \\
\hline
\end{tabular}

Table 7: Correlations: Peer Production Activity and Property Violation Attitudes

Finally, the second research question and the study's two hypotheses explored the relationship between online peer production and support for violations of tangible and intangible property rights. In short, did the experience of engaging in peer production activities online lead students to view violations of intellectual/intangible properties more favourably? And, crucially, what about violations of tangible properties? Was online peer production connected to more favourable attitudes about violations of "real-world" properties as well? The study's two hypotheses predicted positive relationships. In short, the more students engaged in online peer production activities, the more support they would voice for violations of both intangible $(\mathrm{H} 1)$ and tangible $(\mathrm{H} 2)$ properties.

As Table 7 shows, peer production experience was positively related to attitudes about intangible property violations, but was unrelated to attitudes about tangible property violations. In other words, students who had more online peer production experience were indeed more likely to voice support for violations of intangible property violations (including remixing Star Wars, developing a vaccine without permission, hacking a company's website, and putting corporate memos on the web). However, students with more peer production experience were not more likely to voice approval for violations of tangible properties (including squatting on private land, occupying private plazas, and spray-painting billboards). The data thus offer support for $\mathrm{H} 1$ but not $\mathrm{H} 2$.

\subsection{The Influence of Political Ideology}

Overall, online peer production was positively related to attitudes about acquisitive and intangible property violations. To examine the influence of political ideology on these two statistically significant relationships, I conducted a linear regression analysis. This form of anal- 
ysis allows researchers to assess the relative contribution of multiple independent variables on a single dependent variable, in order to determine if a particular bivariate relationship (e.g. between online peer production and intangible property violation attitudes) holds up when the influence of other variables (e.g. political ideology) is introduced. This regression analysis was run in two steps. First, model 1 assessed the influence of peer production on property violation attitudes absent the influence of political ideology. Second, model 2 assessed the influence of peer production while taking into account the relative influence of political ideology. This process would allow me to determine if the influence of peer production on property violation attitudes disappeared when the control variables were introduced. The results of this analysis are reported in Table 8.

\begin{tabular}{|l|l|c|c|c|c|c|c|c|}
\hline & & & Model 1 & & & Model 2 & \\
\hline & & B (SE) & Beta & $\mathbf{p}$ & B (SE) & Beta & p \\
\hline & & & & & & & \\
\hline $\begin{array}{l}\text { Intangible } \\
\begin{array}{l}\text { Property } \\
\text { Attitudes }\end{array}\end{array}$ & Peer production & $.521(.159)$ & .271 & $.001^{* *}$ & $.472(.155)$ & .245 & $.003^{* *}$ \\
\hline & $R^{2}$ & .074 & & & & $-1.252(.372)$ & -.271 & $.001^{* *}$ \\
\hline $\begin{array}{l}\text { Acquisitive } \\
\text { Property } \\
\begin{array}{l}\text { Violation } \\
\text { Attitudes }\end{array}\end{array}$ & Peer production & $.529(.162)$ & .270 & $.001^{* *}$ & & $.479(.155)$ & .245 & $.002^{* *}$ \\
\hline
\end{tabular}

${ }^{* *} p<.01$

Table 8: Effects of Peer Production and Political Beliefs on Violation Attitudes

As Table 8 shows, Model 1 confirmed the correlational analysis reported above: peer production experience enjoyed a significant, positive relationship with attitudes about both intangible and acquisitive violations. Model 2 shows what happened when the influence of political ideology was introduced. First, we can see that scores on the political ideology scale were negatively related to attitudes about both intangible and acquisitive property violations. In other words, and perhaps not surprisingly, students with more conservative political ideologies were less likely to hold positive views of both intangible and acquisitive property violations. But finally and most crucially, by comparing Model 1 and Model 2, we can see that the introduction of the political ideology variable reduced but did not negate the effects of peer production on property violation attitudes. In short, this positive relationship (i.e., the more peer production experience, the more favourable attitudes) remained robust despite the introduction of political beliefs into the regression analysis.

\subsection{Support for Tangible Property Violations among the Most Active Online Peer Producers}

Although the correlation tests above failed to show a significant statistical relationship between online peer production experience and attitudes about tangible property violations (see Table 7), I nonetheless wished to explore the conditions under which this relationship might indeed become significant. In particular, it occurred to me that perhaps the most active online peer producers might hold more favourable attitudes about property violations in the offline world, especially when compared to those who engaged in very little peer production (or none at all). In other words, perhaps there is some "threshold" of online peer production experience, beyond which individuals may begin to translate the lessons of the online world (i.e. where copyrighted works are viewed less as property and more as a common resource 
to be appropriated and transformed) into an offline, real-world context (i.e. voicing more support for outlaws who squat and occupy on private land).

As a result, in order to compare the attitudes of the most active peer-producers to the least active, I used respondents' scores on the "peer production" index to create three groups: heavy, medium, and light peer producers. In this recode, respondents were classified as "light" peer producers if they only engaged in one or fewer of the activities listed in the survey, while "medium" peer producers engaged in two activities, and "heavy" peerproducers engaged in three or more activities. Table 9 shows that 41 percent of the sample were classified as "heavy" producers, while 33 percent were classified as "light" producers.

\begin{tabular}{|l|c|c|}
\hline & N & Percent \\
\hline $\begin{array}{l}\text { Heavy Producers } \\
\text { (3 or more activities) }\end{array}$ & 63 & $41 \%$ \\
\hline $\begin{array}{l}\text { Medium Producers } \\
\text { (2 activities) }\end{array}$ & 40 & $26 \%$ \\
\hline $\begin{array}{l}\text { Light Producers } \\
\text { (zero or one activities) }\end{array}$ & 51 & $33 \%$ \\
\hline $\begin{array}{l}\text { Total } \\
17 \text { missing cases }\end{array}$ & 154 & $100 \%$ \\
\hline
\end{tabular}

Table 9: Categories of Peer Producers

To test if heavy peer producers were more likely than light producers to support violations of tangible property rights, I compared their mean scores on the tangible violation ethics index, computing a t-test for significance. The results reported in Table 10 show that the most active peer producers in the sample (the "heavy" category) were significantly more supportive of violations of tangible property rights, when compared to the least active peer producers (the "light" category). Although such post hoc analysis should be considered as tentative and merely suggestive, it nonetheless raises the possibility that there may be a threshold of sorts when it comes to the effects of peer production on property attitudes more generally-that is, once you become immersed in the practice of collaborative, online peer production, this intensive experience may begin to shape your views on the sanctity of property rights not just online, but offline (in "meatspace") as well.

\begin{tabular}{|l|c|c|}
\hline & N & Mean Index Score \\
\hline Heavy peer producers & 52 & 10.9615 \\
\hline Light peer producers & 48 & 9.5208 \\
\hline
\end{tabular}

$t=-2.604, d f=98, p=.042$

Table 10: Peer Producer Categories and Tangible Property Violation Attitudes

\section{Discussion}

Belief in the sanctity and inviolability of property is a foundational tenet of neoliberal thought (Sandefur 2006). It is taken as given that the social good emerges when common resources are privatized and individuals maximize their self-interest in the use and development of whatever property they have managed to accumulate. Further, this belief in the sanctity of property informs neoliberalism's hostility toward policies protecting workers or the environment. After all, within the confines of neoliberal ideology, such restrictions on private property rights do little more than burden private enterprise and reduce the prosperity of freedomloving people everywhere (Harvey 2005).

At the same time, as Benkler (2006) and Lessig (2002) have argued, the rise of "commonbased peer production" on the web offers a direct challenge to these neoliberal assumptions. 
In the online culture of collaborative peer production, individuals produce valuable collective resources-like Wikipedia or open-source software-in the absence of private property rights. These collective resources are then freely shared so that others might appropriate and transform them as they wish, again without the exclusions of private property. Furthermore, when this freewheeling peer production culture encounters regimes of private property-in the form of copyright restrictions and "cease and desist" letters-the response is usually hostile. Viewed as an illegitimate imposition on a natural right to access common cultural resources (e.g., the images and sounds of popular culture), these remixers and other netizens quickly find ways to subvert property exclusions in order to access the resources they need to achieve their goals. In doing so, as Peñalver and Katyal (2010) argue, these netizens become the latest generation in a long line of property outlaws, contesting the existing scope of private property rights in the hope of writing a more equitable social contract.

This study has explored the wider cultural and political implications of this ferment over online intellectual property rights. In particular, it has explored Lessig's (2008) thesis that, as remixing and commons-based peer production becomes a way of life, and especially as authorities attempt criminalize this now-normative culture, this generation of remixers will begin to question the value of property restrictions and exclusions not just online, but more generally as well (107-09). They may, in fact, translate the lessons of the online world (where valuable resources are created outside of private property rights) to the offline world of "meatspace".

The results of this study provide only partial support for this thesis. Overall, the study suggests experience with online peer production is indeed associated with more positive attitudes about violations of intangible properties. At the same time, however, experience with online peer production was not associated with more positive attitudes about squatting, occupying, or culture-jamming tangible, real-world properties. So it appears that while experience with the culture of commons-based peer production can be indeed be transformative, as yet these transformations in attitudes about private property likely remain confined to the symbolic as opposed to the material realm.

Furthermore, one must also acknowledge the limits of the current study. The convenience sample of students from media studies programs at a single university in the USA limits the study's generalizability. For this reason, future studies in this vein would do well to recruit a random, representative sample across a wider population. In addition, the use of specific scenarios to measure attitudes about particular property violations raises the possibility that different results might have been obtained by using different scenarios. In this regard, future studies might either develop alternative measures of property violation attitudes or test to see if the same patterns hold despite using different scenarios. Finally, and most importantly, the moderate-to-low reliability of the peer production index raises the possibility that the list of activities is too varied and that the index is not tapping reliably into the concept of "peer production." For one, perhaps activities like commenting on a blog and remixing a video are too different to be included on the same scale. More to the point, it may also be that engaging in different forms of peer production carry different ideological and political consequences. In this case, individuals who engage regularly in commons-based peer production might indeed develop more favourable views of property outlaws than do those who engage in more proprietary or corporate-sponsored forms of peer production. For this reason, future research should continue to explore how best to measure participation in peer production and remix culture more broadly in order to tease out some of these political and ideological effects.

Still, despite these limits, the current study does open up avenues for future research and even political practice, particularly for those who wish to see a wider struggle over the current regime of property rights in contemporary life, not merely online but in the tangible, offline world as well. In particular, although it should only be regarded as tentative, the post- hoc analysis comparing heavy to light peer producers is intriguing. Specifically, the finding that the heaviest peer producers ( 3 or more online activities) held significantly more positive attitudes about tangible, "real-world" property violations than the lightest peer producers ( 1 or fewer activities) raises the possibility that individuals may only apply the ethics and values of remix culture (i.e. the values of "cultural commons" and "free sharing") to the offline world 
when they are relatively immersed in this remix culture. This, in turn, suggests that activists who wish to build public support for projects that contest current regimes of both online and real-world property rights might do well to encourage extensive participation in commonsbased peer production projects online.

After all, as Stuart Hall (1986) has argued, political and cultural struggle is about articulation and making connections. In this way, pro-ecology activists attempt to link the practices of industrialism with the reality of wider environmental degradation. For their part, labour and globalization activists work to illuminate the connections between global commodities and the networks of exploited human beings who produced them. In a similar vein, this study suggests that activists who wish to contest the default primacy of private property rights and who wish to promote commons-based modes of resource production should labour to articulate their own political-ideological connections. In short, if strict private property rights are not always necessary for the production and sharing of valued resources online, as the experience of peer production suggests, might not this be the case offline as well? Might not this open up the possibility of creating more collective and commonly held resources-like housing, parks, agricultural resources, and so on-in the "real world"? And if individuals are currently confining these insights about the value of the commons to the realm of intangible or intellectual properties, as was largely the case in this study, they can be surely be encouraged, through political practice, to make new connections and apply these insights elsewhere. This study thus suggests that active peer producers may be at least halfway there: willing in some cases to entertain visions of an online cultural commons. They might just need a little help to take this same imaginative leap in the tangible world.

\section{References}

Andrejevic, Marc. 2003. Reality TV: The Work of Being Watched. Lanham, MD: Rowman and Littlefield Publishers.

Andrejevic, Marc. 2007. iSpy: Surveillance and Power in the Interactive Era. Lawrence, KS: University of Kansas Press.

Bauwens, Michel. 2009. Class and Capital in Peer Production. Capital and Class 97 (Spring): $121-$ 141.

Benkler, Yochai. 2006. The Wealth of Networks: How Social Production Transforms Markets and Freedom. New Haven: Yale University Press.

Bennett, W. Lance, Alexandra Segerberg and Shawn Walker. 2014. Organization in the Crowd: Peer Production in Large-Scale Networked Protests. Information, Communication, and Society 17 (2): 232-260.

Boyle, James. 2003. The Second Enclosure Movement and the Construction of the Public Domain. Law and Contemporary Problems 66: 33-74.

Cohen, Gerald. 1988. History, Labour, and Freedom: Themes from Marx. London: Clarendon Press.

Coombe, Rosemary. 1998. The Cultural Life of Intellectual Properties: Authorship, Appropriation, and the Law. Durham, NC: Duke University Press.

Hall, Stuart.1986. On Postmodernism and Articulation. Journal of Communications Inquiry 10 (2): 4560.

Hardt, Michael and Antonio Negri. 2004. Multitude: War and Democracy in the Age of Empire. New York: Penguin.

Harvey, David. 2003. The New Imperialism. New York: Oxford University Press.

Harvey, David. 2005. A Brief History of Neoliberalism. New York: Oxford University Press.

Heilbroner, Eric. 1986. The Nature and Logic of Capitalism. New York: W.W. Norton and Company.

Jenkins, Henry. 2006. Convergence Culture: Where Old and New Media Collide. New York: NYU Press.

Jenkins, Henry, Sam Ford and Joshua Green. 2013. Spreadable Media: Creating Value and Meaning in a Networked Culture. New York: NYU Press.

Kreiss, Daniel, Megan Finn, and Fred Turner. 2011. The Limits of Peer Production: Some Reminders from Max Weber for the Network Society. New Media and Society 13 (2): 243-259.

Lash, Scott and John Urry. 1994. Economies of Signs and Space. London: Sage.

Lessig, Lawrence. 2002. The Future of Ideas: The Fate of the Commons in a Connected World. New York: Random House. 
Lessig, Lawrence. 2004. Free Culture: How Big Media Uses Technology and the Law to Lock Down Culture and Control Creativity. New York: Penguin.

Lessig, Lawrence. 2008. Remix: Making Art and Commerce Thrive in the Hybrid Economy. New York: Penguin.

McLeod, Kembrew. 2003. Freedom of Expression $₫$ : Resistance and Repression in the Age of Intellectual Property. Minneapolis, MN: University of Minnesota Press.

Meng, Bingchun and Fei Wu. 2013. Commons/Commodity. Information, Communication, and Society 16 (1): 125-145.

Moulier-Boutang, Yann. 2011. Cognitive Capitalism. London: Polity.

Mosco, Vincent. 2009. The Political Economy of Communication: Rethinking and Renewal. 2nd Ed. London: Sage.

Peñalver, Eduardo and Sonia Katyal. 2007. Property Outlaws. University of Pennsylvania Law Review, 155, 1095-1186.

Peñalver, Eduardo Sonia Katyal. 2010. Property Outlaws: How Squatters, Pirates, and Protesters Improve the Law of Ownership. New Haven: Yale University Press.

Rigi, Jakob. 2013. Peer Production and Marxian Communism: Contours of a New Emerging Mode of Production. Capital and Class 37 (3): 397-416.

Sandefur, Timothy. 2006. Cornerstone of Liberty: Property Rights in 21st Century America. Washington: Cato Institute.

Shirky, Clay. 2008. Here Comes Everybody: The Power of Organizing Without Organizations. New York: Penguin.

Wood, Ellen Meikins. 2002. The Origin of Capitalism: A Longer View. London: Verso.

\section{About the Author}

Timothy A. Gibson

Timothy Gibson is an Associate Professor in the Department of Communication and a faculty affiliate in the Cultural Studies PhD program at George Mason University. His research interests include critical media studies, the political economy of communication, and urban studies, and over the past decade he has published articles on media, culture, and the city in variety of communication and cultural studies journals. 